Table 1

Per Cent Alternation for All Groups

\begin{tabular}{lcccc}
\hline & Satiated & $\begin{array}{c}6 \mathrm{~h} \\
\text { Depriva- } \\
\text { vation }\end{array}$ & $\begin{array}{c}22 \mathrm{~h} \\
\text { Depriva- } \\
\text { vation }\end{array}$ & $\begin{array}{c}36 \mathrm{~h} \\
\text { Depriva- } \\
\text { vation }\end{array}$ \\
\hline $\mathrm{V}$ & 26 & 56 & 52 & 66 \\
$\mathrm{D}$ & 70 & 72 & 72 & 84 \\
$\mathrm{O}$ & 46 & 56 & 72 & 50 \\
VDO & 90 & 88 & 92 & 86 \\
C & 30 & 36 & 38 & 34 \\
\hline
\end{tabular}

independent events. Douglas (1964) has argued that the best inddcator of whether an individual $S$ will alternate under certain stimulus conditions is to use the group mean. The fact that an individual $S$ does not alternate on a given pair of trials does not change the probability of that animal's alternating on a following pair of trials. We found no difference between days and found that all $S s$ in a given condition alternated at approximately the same rate. Douglas (1964) further argued that repeated trials can be considered independent as far as the analysis of alternation data is concerned. Thus, while the individual trials in a pair may not be independent, the results of a number of pairs for a given $S$ are assumed to be independent. Following this line of argument, the data were pooled over Ss rather than days and an arcsin transformation was applied to the proportion scores. Analysis of variance showed significant effects for both drive level $(\mathrm{F}=4.47, \mathrm{df}=3 / 80, \mathrm{p}<.01)$ and cue condition $(F=59.23, \mathrm{df}=4 / 80, \mathrm{p}<.01)$. The Drive Level by Cue Group interaction was also significant $(F=2.26, \mathrm{df}=12 / 80$, $\mathrm{p}<.05)$. A Duncan range test between drive levels revealed a significant difference between the satiated Ss and all deprived animals but no significance was found between the different deprivation levels when all cue groups were combined. There were no significant differences across drive levels within the all-cue VDO group or the no-cue $C$ group, but the $C$ group had significantly lower rates of alternation than the VDO group, as predicted. The consistently below-chance performance of the $\mathrm{C}$ group raises some questions about the assumption that chance behavior is $50 \%$ in a two-choice task, at least when middle-ear-diseased animals are used.

In order to analyze the interaction, the Student $t$ test was used although the use of the $t$ under these conditions violates some of the assumptions of the test. There are 40 comparisons of which 36 were significantly different ( $p<.05$, one-tailed test) The four nonsignificant comparisons were the following: $\mathrm{C}-\mathrm{V}$ for $\mathrm{O} \mathrm{h}$ deprivation, $\mathrm{O} \cdot \mathrm{V}$ for $6 \mathrm{~h}$ deprivation, O-D for $22 \mathrm{~h}$ deprivation, and VDO-D for $36 \mathrm{~h}$ deprivation.

$$
\text { DISCUSSION }
$$

The low alternation rates of the $\mathrm{V}, \mathrm{O}$, and
C groups may be due in part to the fact that the middle-ear-diseased rats were under some form of stress and therefore were less inclined to alternate. The fact remains that these Ss do respond to visual and odor cues and therefore the results cannot be accounted for solely in terms of the fact that some of the animals used in the experiment were "sick." Since food deprivation may also be considered a type of stress, it is interesting to note that al ternation increased under certain levels of this type of "stress."

The results of the present study provide evidence that the extent to which cues are utilized in the spontaneous alternation situation is directly affected by the drive level of the organism. Generally, an increase in drive may be said to increase the effectiveness of specific cues, with the exception of the odor, at high drive levels. The predictions were generally confirmed and the results were generally consistent with Douglas's earlier work on satiated rats. The effectiveness of visual stimuli at higher drive levels and the increased effectiveness of other cues extend the Douglas findings and provide evidence for the contention that drive may have an organizing effect. The results question Bruner, Matter, \& Papanek's (1955) and Easterbrook's (1959) contention that increased drive leads to a reduction in the number of cues utilized.

Douglas argues that the Dember \& Earl (1957) model of stimulus selection does not account for his data. Dember and Earl suggest that organisms respond to the changed or more novel aspect of the stimulus situation rather than avoid that aspect of the stimulus situation the organism has previously experienced. Whether response to the more novel is governed by odor or direction cues is immaterial. When appropriate procedures are used to insure that the visual stimulus for one alternative is more novel than the visual stimulus of the other alternative, response to visual change is observed. Drive levels appear to influence whether a given cue or combination of cues is effective in guiding alternation. At least for the present data, the Dember and Earl theory still remains a parsimonious and viable explanation of the alternation phenomenon.

\section{REFERENCES}

BAKER, J. G., \& FR ANKEN, R. E. Alternation as a function of drive level and visual complexity. Psychonomic Science, 1967, 8, 91-92.

BRUNER, J. S., MATTER, J., \& PAPANEK, M.L. Breadth of learning as a function of drive level and mechanization. Psychological Review, $1955,62,1-10$.

DEMBER, W. N., \& EARL, R. W. Analysis of exploratory, manipulatory and curiosity behaviors. Psychological Review, 1957, 64, 91-96.

DOUGLAS, R. J. Spontaneous alternation cues. Unpublished doctoral dissertation, University of Michigan, 1964.

DOUGLAS, R. J. Spontaneous altemation and middle-ear disease. Psychonomic Science, 1966a, 4, 243-244.

DOUGLAS, R. J. Cues for spontaneous alternation. Journal of Comparative \& Physiological Psychology, 1966b, 62, 171-183. EASTERBROOK, J.A. The effect of emotion on cue utilization and organization of behavior. Psychological Review, 1959, 66, 183-201.

FRANKEN, R. E., \& BAKER, J. G. Drive level and cue utilization in spontaneous altemation. Psychonomic Science, 1967, 8, 89-90.

\section{NOTE}

1. This investigation was supported in part by the National Research Council of Canada, Grant APA-170, to the first author. Part of the data was reported by J. B. Baker in a thesis submitted in accordance with the requirements for the MA degree of the University of Calgary.

\title{
Early experience and visual cliff behavior in the Mongolian gerbil
}

(Meriones unguiculatus) : "I

D. D. THIESSEN, G. LINDZEY, and A. COLLINS, University of Texas, Austin, Tex. 78712

Exposure of male and female gerbils to "flat" and "cliff" living environments from 30 to 51 days of age modifies subsequent visual cliff behavior. Prior experience with a cliff decreases latency to respond. This is especially apparent if the early environment has a pattern similar to the visual cliff on which the test is made. Descent from a deep cliff is more apt to occur in animals with previous cliff experience with a minimum of visual depth cues. 
Table 1

Number of Ss Responding to the Shallow (S) and Deep (D) Side of the Visual Cliff

\begin{tabular}{llllllllllllllllllll}
\hline & Trial & \multicolumn{1}{c}{} & 1 & & 2 & & 3 & & 4 & & 5 & & 6 & & 7 \\
\cline { 2 - 15 } Cage Condition & Choice & S & D & S & D & S & D & S & D & S & D & S & D & S & D \\
\hline Patterned Cliff & & 9 & 1 & 10 & 0 & 10 & 0 & 10 & 0 & 9 & 1 & 9 & 1 & 9 & 1 \\
Unpatterned Cliff* & & 8 & 1 & 9 & 0 & 7 & 2 & 8 & 1 & 5 & 4 & 8 & 1 & 4 & 5 \\
Unpatterned Flat & & 8 & 0 & 9 & 0 & 10 & 0 & 9 & 1 & 10 & 0 & 9 & 0 & 8 & 2 \\
\hline
\end{tabular}

* One animal lost before test

In an earlier paper we reported that the Mongolian gerbil (Meriones unguiculatus) was deficient in visual cliff behavior (Thiessen, Lindzey, Blum, Tucker, \& Friend, 1968). We attributed this deficit in depth discrimination to a species-specific visual characteristic or to emotional factors. Subsequent investigation reveals that the gerbil indeed possess depth discrimination but that it is influenced by a complex interaction between visual and tactual cues, with learning and emotion playing a relevant part (Collins, Lindzey, \& Thiessen, 1969).

In brief, when a gerbil descends from a height it must either sense that the height is not great (visual recognition) or determine that a solid surface is nearby (tactual recognition). Failure to confirm either condition will retard the descent, but verification of a solid surface is sufficient for a descent despite conflicting visual cues. When it is apparent to the animal that a solid surface is present, later responses will be more rapid and will lack the quality of emotional hesitation.

This experiment demonstrates that exposure to flat and cliff surfaces during early life can significantly modify visual cliff behavior in later life.

\section{SUBJECTS AND APPARATUS}

Thirty gerbils (Meriones unguiculatus), of equal sexes, were used in this experiment. Five of each sex were assigned to each of three cage conditions where they lived from 30 to 51 days of age. The three conditions refer to the presence or absence of a cliff and the presence or absence of checkerboard squares. All cages were $11 \times 26 \times 14 \frac{1}{2}$ in., and were covered by wire rod tops with food and water bottles available.

In the unpatterned cliff condition, the cage was separated by a $91 / 2$-in. step (cliff). A ramp (14 $\times 3 \frac{1}{2}$ in.) connected the upper and lower compartments, but otherwise the two sides were separated by a sheer drop. The cage was painted gray. In the patterned cliff condition, the cage was identical to the first except that it was painted in $3 / 4$-in. black and white checkerboard squares. In the unpatterned flat condition, the cage was of similar dimensions to the other two but possessed no cliff. The top was lowered to 5 in. off the floor to equate for total living area.
The visual cliff used for testing was the same as described by Thiessen et al (1968), except that the center rail was $11 / 2$ in. above the glass and was covered with $1 / 4$-in. wire screening.

\section{PROCEDURE}

At 52 days of age, when the gerbils had been differentially exposed to the living conditions for 21 days, all animals were separated into individual holding cages and tested for cliff responses on that day and the succeeding day. Five trials were given on the first test day and two on the second. For reasons of counterbalancing and individual latencies, the intertrial interval was approximately $5 \mathrm{~min}$ on the first day and $2 \mathrm{~min}$ on the second. Choice of shallow or deep side of the visual cliff and latency to descend were recorded. The maximum latency was arbitrarily fixed at $5 \mathrm{~min}$. One animal was lost from the unpatterned cliff condition prior to testing.

Table 2

Mean Latency to Descend

\begin{tabular}{lccccc}
\hline \multicolumn{5}{c}{ Cage } & \multicolumn{5}{c}{ Trial } \\
\cline { 2 - 7 } \begin{tabular}{l} 
Condition \\
\cline { 2 - 6 }
\end{tabular} & 1 & 2 & 3 & 4 & 5 \\
\hline $\begin{array}{l}\text { Patterned } \\
\begin{array}{l}\text { Cliff } \\
\text { Unpatterned }\end{array}\end{array}$ & .074 & .073 & .099 & .113 & .135 \\
$\begin{array}{l}\text { Cliff } \\
\begin{array}{l}\text { Unpatterned } \\
\text { Flat }\end{array}\end{array}$ & .459 & .270 & .233 & .362 & .303 \\
\hline
\end{tabular}

\section{RESULTS}

Number of shallow and deep responses are shown in Table 1 and latencies to descend for the first five trials are given in Table 2. Gerbils in all three groups clearly prefer the shallow side of the visual cliff. However, whereas only two and three animals in the patterned and flat conditions ever went to the deep side, all nine animals in the unpatterned cliff condition descended to the deep side on one or more of the seven trials $\left(\chi^{2}=15.56, \mathrm{df}=2, \mathrm{p}<.001\right)$.

Latencies to descend ranked in the same order on all trials: unpatterned flat $>$ unpatterned cliff $>$ patterned cliff. A two-way mixed model analysis of variance indicated that the overall cage condition was significant $(F=4.43, \mathrm{df}=2 / 27, \mathrm{p}<.05)$. The error variance for the unpatterned flat cage was much higher than for the other two conditions; hence it would be misleading to base unpatterned flat vs unpatterned cliff and unpatterned cliff vs patterned cliff comparisons on the overall error term. Hence these comparisons were tested using the error terms for the groups compared only. (1) Mean latency for the patterned cliff condition was significantly lower than for the unpatterned cliff condition $(F=32.94$, df $=1 / 18, p<.001)$. (2) Mean latency for the unpatterned cliff condition was not significantly lower than for the unpatterned flat condition $(F=2.67$, $\mathrm{df}=1 / 18, \mathrm{p}>.10$ ). This result, somewhat surprising in view of the large and consistent difference in means, is due to the large error variance in the unpatterned flat condition which results from a few very high scores on each trial.

\section{DISCUSSION}

The marked difference in latencies to descend between the patterned cliff and unpatterned cliff conditions was due to the consistency of the patterned cliff gerbils in descending more quickly. This indicates that the early experience of visual depth stimuli in the patterned cliff cage exerts a rather uniform facilitatory effect on later descent. The extreme shortness of the patterned cliff latencies suggests that the effect was rather specifically related to experience of depth stimuli and was not merely the result of greater general visual responsiveness.

More animals from the unpatterned cliff condition descended to the deep side than from either of the other conditions. This would seem to indicate that these animals were relying more on tactual cues than the other groups. This is consistent with their early experience with a cliff marked by only minimal visual cues.

The results of this study support our earlier conclusions that the gerbil can respond appropriately to the cliff situation by relying on either visual or tactual stimuli. The present study has shown that the effectiveness of these stimuli in regulating the descent response can be modified by manipulating the early environment.

\section{REFERENCES}

COLLINS, A., LINDZEY, G., \& THIESSEN, D.D. The regulation of cliff responses in the Mongolian gerbil (Meriones unguiculatus) by visual and tactual cues: I. Psychonomic Science, $1969,16,227-229$.

THIESSEN, D. D., LINDZEY, G., BLUM, S., TUCKER, A., \& FRIEND, H.C. Visual behavior in the Mongolian gerbil (Meriones unguiculatus). Psychonomic Science, 1968, 11 . 23-24.

\section{NOTE}

1. This research was supported in part by NIMH Grant MH 14076-02 and NIMH Research Development Award MH 11, 174-02 to Delbert D. Thiessen. 